\title{
La descapitalización de los sujetos migrantes: el caso de las mujeres mexicanas indocumentadas en Phoenix-Arizona
}

\section{Decapitalization of the Immigrant Subject: The Case of Undocumented Mexican Women in Phoenix-Arizona}

Tania Lizeth Bonilla ${ }^{1}$

\section{RESUMEN}

Este artículo explica cómo la economía de la "ilegalidad" no solo produce mano de obra flexible y precarizada, sino que se sostiene en un proceso de descapitalización continuo de los sujetos migrantes, que incluye desde prácticas sutiles, como pagar multas por infracciones de tránsito, hasta otras más violentas, como el encierro indefinido en un centro de detención. A través de entrevistas realizadas a mujeres mexicanas indocumentadas que habitan en Phoenix, Arizona, se revela la forma en que la deportabilidad y la detenibilidad producen una descapitalización económica y una desposesión de seguridad física y psicológica que tiene particulares connotaciones de género.

Palabras clave: 1. economía de la "ilegalidad", 2. género, 3. deportabilidad, 4. Phoenix, 5. Arizona.

\section{ABSTRACT}

This article explains how the economy of "illegality" produces not only a flexible and precarious labor force but in a continuous process of continuous decapitalization of immigrant subjects ranging from subtle practices, such as traffic ticket fines, to more violent ones, which include the indefinite confinement in a detention center. Through interviews with undocumented Mexican women living in Phoenix, Arizona, it is revealed how deportability and detainibility produce economic decapitalization and dispossession of physical and psychological security that has gendered connotations.

Keywords: 1. economy of "illegality," 2. gender, 3. deportability, 4. Phoenix, 5. Arizona.

Fecha de recepción: 12 de noviembre de 2018

Fecha de aceptación: 11 de junio de 2020

Fecha de publicación: 15 de abril de 2021

\footnotetext{
${ }^{1}$ FLACSO-Ecuador, tlbonillafl@flacso.edu.ec, https://orcid.org/0000-0002-9708-6044
}

Migraciones Internacionales es una revista digital anual editada por El Colegio de la Frontera Norte. https://migracionesinternacionales.colef.mx 


\section{INTRODUCCIÓN}

En una investigación reciente ${ }^{2}$ sobre las estrategias individuales y colectivas desarrolladas por mujeres mexicanas indocumentadas en el barrio de Maryvale-Phoenix, Arizona, frente a la amenaza de la deportación, con frecuencia surgieron relatos sobre el endeudamiento continuo que supone tanto evitar dicha amenaza, como estar inmersa en ella. Es decir, evitar una posible detención, pero también el pago constante de multas, implica tratar de no llamar la atención, tomar todas las precauciones posibles al conducir, e incluso caminando, lo cual implica invisibilizarse lo máximo posible en el espacio público.

Si bien los hombres son más propensos a ser deportados y detenidos que las mujeres (Golash-Boza y Hondagneu-Sotelo, 2013), nuestro interés en las experiencias personales de mujeres mexicanas indocumentadas se centra en comprender de qué manera se ven inmersas en un proceso de feminización de la supervivencia (Sassen, 2003). Si además se considera la desigualdad que genera su estatus legal y su género (Dreby, 2015), las mujeres se enfrentan a una crisis multidimensional que deviene de la reproducción social (Narotzky, 2004).

La investigación nos permitió constatar la forma en que las mujeres migrantes indocumentadas están expuestas a procesos de descapitalización y desposesión dentro de la economía de la "ilegalidad", no solo como mano de obra flexible, barata y precarizada, sino también como objetos de control a través del aparato económico que circunda la detención y la deportación. Lo que nos interesa dilucidar aquí es que los procesos de descapitalización son constantes y forman parte intrínseca de esa economía que se genera en torno a la "ilegalidad" migratoria. Esta reflexión surge ante la necesidad de ampliar teóricamente qué es la economía de la deportación, la detención o la clandestinidad (De Genova, 2016 y Calavita, 2004).

Proponemos que la economía de la "ilegalidad" se sustenta a través de la acumulación por desposesión (Harvey, 2003) ya que este régimen de gobierno ha transformado a los y las migrantes en mercancías para iniciar nuevos procesos de acumulación de capital. Partimos de una perspectiva de género para entender los discursos feminizados que están inmersos en la economía de la "ilegalidad" y los diversos procesos de descapitalización. Al mismo tiempo, resaltamos la capacidad de acción, agencia y resistencia de las mujeres migrantes.

Con base en el marco analítico de la economía de la "ilegalidad", queremos aportar a la discusión de investigaciones recientes en torno a la deportabilidad, las consecuencias y los efectos de la deportación, y cómo esta última irrumpe la vida familiar, generando consecuencias a mediano y largo plazo (Golash-Boza, 2015, 2019; Boehm, 2016; Dreby,

2 El presente artículo forma parte de la tesis de maestría denominada: "Vivir en el limbo": Las formas de afrontar el régimen de deportación de las migrantes mexicanas indocumentadas en Phoenix-Arizona de la Facultad Latinoamericana de Ciencias Sociales, Flacso Ecuador. El trabajo de campo se desarrolló en los meses de febrero y marzo de 2018. 
2015). Además, no se ha puesto en debate la producción de la descapitalización de los sujetos migrantes desde una perspectiva de género. Cabe mencionar que, al referirnos a los sujetos migrantes, estamos haciendo generalmente alusión el sujeto de estudio de la investigación que son mujeres migrantes indocumentadas de nacionalidad mexicana.

El contexto local de Phoenix, Arizona, en torno a la aplicación de política migratoria ha dado forma a la vida cotidiana de los y las migrantes. Precisamente, ha existido una polémica en la aplicación de leyes y el accionar de la policía que se ha centrado en una constante persecución y hostigamiento en contra de la comunidad migrante, la cual se intensificó con la aprobación de la ley Arizona Senate Bill 1070 (SB1070 en adelante).

El artículo está estructurado de la siguiente manera. En un primer apartado realizamos una breve discusión teórica. En una segunda sección exponemos la metodología y las técnicas aplicadas. Enseguida presentamos el contexto entorno a la política migratoria de Phoenix, Arizona. En el cuarto apartado abordamos la discusión sobre cómo ocurren los procesos de descapitalización a través de una de las tácticas más comunes y sutiles, que son las paradas de tránsito. En la quinta parte examinamos qué sucede cuando los sujetos migrantes están inmersos en un proceso de deportación, realizando un análisis de género explicamos cómo se configura un proceso de acumulación de capital a través de la penalización de la migración, de qué manera produce una crisis multidimensional en la vida de las mujeres migrantes y, a su vez, denotar su capacidad de acción. Finalmente, exponemos las conclusiones.

\section{COORDENADAS TEÓRICAS}

Utilizando las teorías de Michael Foucault, diversos autores han estudiado las tecnologías de poder y control que se han creado para regular los flujos migratorios a partir de la categoría de gubernamentalidad (Coutin, 2003; De Genova, 2002; De Genova y Peutz 2010; Martín, 2011). Dentro de los estudios migratorios, la gubernamentalidad es entendida como una forma de gobernar en la que se configuran diversas tecnologías de poder y control, procedimientos, discursos y estrategias de vigilancia, que tienen como objetivo común controlar y vigilar la vida de los individuos y la población en general (Martín, 2011). Así, existen diversas tecnologías de poder y control para controlar los flujos migratorios, por ejemplo: los visados, las redadas de trabajo, la creación de centros de detención, las tecnologías biométricas y la deportación.

Las tecnologías de poder y control se sustentan en políticas migratorias, y bajo el discurso de la "ilegalidad" tienen como objetivo el disciplinamiento de los cuerpos de la población migrante. De Genova (2002) señala que la intención de los Estados nacionales es mantener a la población migrante en la "ilegalidad", con el fin de producir mano de obra barata y flexible, despojada de todo derecho y excluida de la vida política, pero, paradójicamente, "incluida" a través de la exclusión. La producción legal de la "ilegalidad" ha convertido a 
los y las migrantes en el centro de procesos de acumulación de capital, convirtiéndolos en trabajadores dóciles, desechables, y a su vez esos cuerpos criminalizados son los que enriquecen a las cárceles y centros de detención privados (Lee, 2018). En este sentido, De Genova (2016) propone la categoría de economía de la deportación y detención, mientras que Kitty Calavita (2004) la de economía de la alteridad. Los dos autores sostienen que las lógicas de esta economía se sustentan en una economía de poder.

Para De Genova (2016), la economía de la deportación y la detención forma parte de un régimen de deportación cuyas características son la deportabilidad y la detenibilidad. Es decir, en este régimen de gobierno se determina quiénes son aceptados o rechazados en una sociedad. Para comprender qué es la deportabilidad y la detenibilidad, consideramos clave incluir la reflexión teórica de Kanstroom (2000), quien explica cómo los Estados nacionales controlan los flujos migratorios aplicando un modelo de control social continuo y un modelo fronterizo. En este último modelo, el mecanismo principal de los Estados para el control de las fronteras es la deportación. Mientras que en el modelo de control social continuo, es la deportabilidad, como estrategia de la biopolítica, la que funciona como dispositivo de seguridad que disciplina los cuerpos ante la amenaza de la deportación (De Genova y Peutz, 2010). Como señala Aquino (2015, p. 81) "la deportabilidad graba en los cuerpos de los migrantes los efectos prácticos del control de la frontera".

De Genova y Peutz (2010) señalan que la efectividad del régimen de deportación está en la deportación de unos pocos, junto con la constante movilidad diaria de otros, lo que produce y mantiene la "ilegalidad" migrante no solo como un estado jurídico anómalo, sino como un modo de ser práctico. Por lo que la "ilegalidad" migratoria se vive a través del sentido palpable de la deportabilidad, es decir, mediante la posibilidad constante de ser expulsado de un Estado (De Genova, 2002).

La deportabilidad se sustenta en otros dispositivos que acentúan y materializan esta condición, como es la detenibilidad. Como ya lo mencionamos, la detención es una tecnología de poder y control; bajo este régimen global de deportación, control y seguridad, se ha impulsado estratégicamente una expansión de la detención de los y las migrantes (Martin, 2011). La detenibilidad se materializa en la vida cotidiana como una realidad simple e inevitable que deriva de algún tipo de "violación", evidente o no, de la ley. Los y las migrantes sometidos a la detención generalmente son "culpables" de su estatus "ilegal" y son penalizados por el hecho de ser migrantes (De Genova, 2016).

A partir de este lente teórico, adoptamos la categoría de la economía de la "ilegalidad" en contraposición a los otros autores, ya que se entiende que la lógica de acumulación de capital de la fuerza de trabajo de los y las migrantes está determinada directamente por la "ilegalidad" de los sujetos producida por el Estado, mas no por su condición de sujetos deportables. Esto no significa que la deportabilidad y la detenibilidad estén excluidas, pues estas son categorías que refuerzan la configuración de sujetos explotables expuestos a un escenario de desigualdad social y de constante despojo económico. Así, la economía de la 
"ilegalidad" se sustenta a través de la acumulación por desposesión (Harvey, 2003), ya que ha transformado a los y las migrantes en mercancías para iniciar nuevos procesos de acumulación de capital a través de centros de detención privados $\mathrm{y}$, a su vez, criminalizando sus cuerpos y desposeyéndolos de seguridad física, emocional y psicológica (Lee 2018). La desposesión también puede ser entendida a partir de la propuesta de Butler y Athanasiou (2013) que, en términos éticos y políticos, está en relación directa con la desposesión de derechos básicos y la dignidad de los seres humanos, lo que provoca la vulnerabilidad de los sujetos migrantes diferenciada por género.

El marco analítico sobre la economía de la "ilegalidad" debe ser entendido en relación con otras categorías de análisis, como es el caso del género. Tomamos la definición de Pujal y Amigot (2010, p. 131) al teorizar al género como un dispositivo de poder, resaltando siempre su interacción con otros dispositivos como la raza/etnia, el estatus legal, la nacionalidad, y otras tecnologías de control como la deportabilidad y la detenibilidad, que buscan regular los cuerpos de los y las migrantes.

En este sentido, la condición de subordinación y de vulnerabilidad que genera la "ilegalidad", la deportabilidad y la detenibilidad, se refleja como un estigma en la vida de los sujetos migrantes, pero de manera diferenciada (Boehm, 2016; Dreby, 2015). Específicamente, en el caso de las mujeres migrantes indocumentadas, y tomando en cuenta las desigualdades sociales y de género, son ellas quienes se enfrentan a diversas formas de exclusión que acarrea la economía de la "ilegalidad". De esta manera, la forma en la que operan estos dispositivos de poder y tecnologías de control también nos confronta con la capacidad de agencia y acción que tienen las mujeres migrantes indocumentadas.

Nos posicionamos en la definición de agencia social propuesta por Mahmood (2008) al exponer que si bien existen experiencias de dolor, sufrimiento, y en el contexto migratorio a las mujeres migrantes se las ha etiquetado como sujetos vulnerables, existen diversas formas de habitar en las normas, y de resistir a las mismas. Por lo anterior, la agencia social nos evoca esa capacidad de acción que tienen las mujeres migrantes para poder sobrevivir al orden social impuesto.

\section{SOBRE LA METODOLOGÍA}

La construcción metodológica de la investigación parte de un enfoque cualitativo. Utilizamos el método etnográfico a partir de lo que propone Geertz (1987) como una descripción densa. Nos interesa poner especial atención en las experiencias y vivencias que atraviesan las mujeres mexicanas indocumentadas al ser un blanco de deportación. A su vez, develar de qué forma la amenaza de la deportación y la aplicación del modelo de control social continuo llevan consigo una connotación de género.

Esta investigación se centra en migrantes mexicanas indocumentadas residentes en Phoenix, Arizona. Nos centramos en mujeres de esta nacionalidad ya que, al momento de 
realizar el trabajo de campo, el contacto inicial se produjo a través de dos organizaciones pro migrantes en Phoenix: Center of Neighborhood Leadership (CNL en adelante) y Puente Human Rights Movement (Puente en adelante), donde la mayoría de las personas que acudían a las juntas semanales para empoderamiento comunitario eran de nacionalidad mexicana. El hecho de ser mexicanas provoca también que las estrategias frente a los procesos de deportación o a su amenaza sean distintos a las de otras nacionalidades, ya que el escenario histórico, geográfico, político y diplomático con México es diferente al de otros países de Latinoamérica. Se estudió a mujeres que migraron alrededor de los años noventa desde zonas rurales de México, que forman parte de familias con estatus legal mixto; la mayoría tienen al menos un hijo/a, están insertas en el mercado de trabajo de limpieza y cuidado, y son parte de una organización promigrante desde que atravesaron directa o indirectamente por un proceso de deportación. ${ }^{3}$ El cuadro 1 expone sucintamente las características demográficas del sujeto de estudio.

Cuadro 1. Características demográficas

\begin{tabular}{|c|c|}
\hline Edad & Cantidad de mujeres \\
\hline de 30 a 40 años & 3 \\
\hline de 40 a 50 años & 15 \\
\hline de 50 a 60 años & 11 \\
\hline más de 60 años & 1 \\
\hline Estado civil & \\
\hline Casada & 19 \\
\hline Separada & 5 \\
\hline Divorciada & 2 \\
\hline Soltera & 3 \\
\hline Viuda & 1 \\
\hline \multicolumn{2}{|c|}{ Número de hijos } \\
\hline 1 a 2 & 8 \\
\hline 3 a 4 & 16 \\
\hline más de 4 & 6 \\
\hline
\end{tabular}

Fuente: Elaboración propia.

\footnotetext{
${ }^{3}$ Entendemos a la deportación, a partir de la propuesta de Boehm (2016), como un proceso social que no solo afecta a los sujetos migrantes que son deportados sino se extiende a los miembros de la familia y comunidad.
} 
Decidimos enfocarnos en el barrio de Maryvale, de la ciudad de Phoenix, Arizona, que tiene el mayor porcentaje de población hispana de la ciudad, con un 85 porciento según The Demographic Statistical Atlas of the United States (2017). Con respecto a la espacialidad, tomamos en cuenta dos escalas. La primera, y más importante, es de nivel estatal y local. Se tomó en cuenta las políticas migratorias que empiezan a desarrollarse a partir de 2010 en torno a la Ley SB1070 y, a su vez, se consideraron las leyes posteriores a este año que impulsaron la consolidación de esta. Por otro lado, fue clave abordar el nivel federal a partir de las modificaciones legislativas realizadas por Donald Trump y dirigidas a profundizar los procesos de deportación de migrantes indocumentado/as desde enero de 2017 hasta inicios de septiembre de 2017, con el intento de terminación del DACA.

Las técnicas de recolección de información utilizadas fueron el análisis documental de políticas migratorias, tres entrevistas a profundidad dirigidas a expertos legales de migración y dos entrevistas dirigidas a la directora de CNL y Puente, así como 30 entrevistas semiestructuradas dirigidas a mujeres y cinco a hombres. Sobre las entrevistas semiestructuradas debemos señalar que duraron aproximadamente dos horas y la mayoría fueron realizadas en sus domicilios. Por otro lado, los hombres entrevistados son pareja de estas mujeres y, a su vez, son indocumentados. Las entrevistas con ellos duraron alrededor de veinte minutos debido a que existía mucha resistencia en entablar una conversación sobre sus dificultades en torno a su situación migratoria. Finalmente, se realizó observación participante, que consistió en acudir a las juntas semanales de las organizaciones, realización de talleres y acompañamiento a check in. El check in, significa acompañar a aquellas personas que están en proceso de deportación y que deben presentarse regularmente a las oficinas de US Immigration and customs Enforcement (ICE en adelante) para firmar y comprobar que siguen en Phoenix, mientras su caso sigue abierto.

Respecto a la sistematización de la información, se optó por realizar perfiles de caso. Para su construcción se tomaron en cuenta las siguientes variables: si las mujeres han sido deportadas o están atravesando por un proceso de deportación, si algún familiar o ser querido ha sido deportado o está atravesando por un proceso de deportación. En este sentido, 7 de las 30 mujeres entrevistadas estaban en proceso de deportación. Por otro lado, 23 de las 30 mujeres entrevistadas tenían algún familiar cercano que había sido deportado o estaba en proceso de deportación. El cuadro 2 expone detalladamente esta información. 
Cuadro 2. Deportación, procesos de deportación y causas

\begin{tabular}{|c|c|c|c|}
\hline \multicolumn{2}{|l|}{ 1. Mujeres entrevistadas } & \multicolumn{2}{|l|}{ Causas de detención } \\
\hline En proceso de deportación & 7 & Detención en la frontera & 2 \\
\hline $\begin{array}{l}\text { Con un familiar o ser querido } \\
\text { deportado o en proceso de deportación }\end{array}$ & 23 & $\begin{array}{l}\text { Detención al conducir por perfil racial, sin licencia } \\
\text { Detención al conducir por embriaguez }\end{array}$ & $\begin{array}{l}4 \\
1\end{array}$ \\
\hline \multicolumn{4}{|l|}{ 2. Familiares en proceso de deportación } \\
\hline Hijo/a & 1 & Detención al conducir con embriaguez & 2 \\
\hline Pareja & 2 & Detención al conducir con exceso de velocidad & 1 \\
\hline Mejor amiga & 1 & Detención en la frontera & 1 \\
\hline \multicolumn{4}{|l|}{ 2.1. Situación actual } \\
\hline $\begin{array}{l}\text { Detenidos en centros de detención } \\
\text { migratorios }\end{array}$ & 2 & & \\
\hline Salida bajo fianza & 2 & & \\
\hline \multicolumn{4}{|l|}{ 3. Familiares deportados } \\
\hline Expareja & 5 & Detención al conducir por perfil racial, sin licencia & 9 \\
\hline Cuñado/a & 3 & Detención al conducir con exceso de velocidad & 1 \\
\hline Hermano/a & 7 & Redada de trabajo & 6 \\
\hline Hijo/a & 2 & Cargos por narcotráfico & 3 \\
\hline Sobrino/a & 2 & & \\
\hline
\end{tabular}

Fuente: Elaboración propia

Los testimonios presentados en este artículo fueron seleccionados de tal manera que ilustren cuatro situaciones relacionadas con los procesos de descapitalización que están en relación directa con la deportabilidad y detenibilidad. En este sentido, nos centramos en situaciones de la vida cotidiana, como por ejemplo detenciones debido a un perfil racial en el espacio público, interrogatorios con agentes migratorios, experiencias en cárceles locales y centros de detención migratorios. Cabe mencionar que todos los nombres utilizados en este documento son seudónimos, a fin de proteger la identidad de los y las entrevistadas.

\section{POLÍTICA MIGRATORIA LOCAL}

Los y las migrantes en Estados Unidos se enfrentan a un sistema de políticas migratorias que incluye un componente exterior, en forma de frontera militarizada, y un componente interior, en forma de múltiples fronteras internas (Menjívar, 2014). Arizona ha sido, en este sentido, uno de los estados que ha intentado sobrepasar los lineamientos federales en materia migratoria con la promulgación de la SB1070 en el año 2010. En la misma línea, la aplicación de las políticas antinmigrantes en la ciudad de Phoenix ha sido polémica debido a la forma en la que la policía local las interpreta y aplica, además del accionar de una de las 
figuras más controversiales como lo fue la del Sheriff Joe Arpaio. En esta sección nos centraremos en explicar sucintamente estos dos puntos.

La aprobación de la SB1070 deviene de la emisión de más de cuarenta leyes antinmigrantes desde 2004 (Torre, 2016; Montoya, Ochoa y Woo, 2014). El objetivo principal y, redactado en la primera sección de dicha ley, es el attrition through enforcement el cual consiste en que los y las migrantes "ilegales" se vean obligados a desistir y regresar a su país voluntariamente o auto expulsarse (Cornelius, 2012). Además, varios activistas denominaron a la SB1070 como "la máquina de hacer dinero".

Una de las características de la maquinaria de la deportación es crear una infraestructura carcelaria. Las empresas privadas han encontrado un negocio en el arresto indefinido de migrantes indocumentado/as y aquellos que solicitan asilo. Corrections Corporations of America (CCA) y Geo Group son las empresas más grandes que el Department of Homeland Security (DHS en adelante) y el US Immigration and Customs Enforcement (ICE en adelante) contratan para alojar, detener, vigilar y procesar migrantes para la deportación (Gilman y Romero, 2018; Gómez, Menjívar y Staples, 2017). Estas empresas tienen vínculo directo con el American Legislative Exchange Council (ALEC), institución conservadora que promueve, por medio de lobby político ${ }^{4}$, la aprobación de leyes antiinmigrante en todo el país (Gómez et al., 2017).

En Phoenix-Arizona funcionan dos centros de detención, Eloy Detention Center y Florence Correctional Center, las dos son cárceles privadas manejadas por Corrections Corporations of America. Están ubicadas a 40 millas de la ciudad, donde no hay transporte público, lo cual dificulta visitar a la población migrante detenida. Eloy, creado en 1994, es el tercer centro de detención de migrantes más grande del país y el de peor reputación a nivel nacional ${ }^{5}$.

Respecto a la aplicación de las leyes migratorias en Phoenix, uno de los principales problemas es el accionar de la policía local. Tal es el caso del Acuerdo $287 \mathrm{~g}$ firmado por el Condado de Maricopa que estuvo vigente desde el año 2003 hasta el 2012. Este tipo de acuerdo daba facultades a policías locales para cuestionar el estatus migratorio de cualquier persona $\mathrm{y}$, a su vez, permitía que el ICE estuviera en las cárceles locales, facilitando la identificación de migrantes indocumentado/as que hubieran cometido delitos menores como manejar sin licencia. El DHS canceló el acuerdo debido a constantes denuncias de detención de migrantes respecto al perfil racial (Meissner, Kerwin, Chishti y Bergeron, 2013).

\footnotetext{
${ }^{4}$ El senador Russell Pearce, quien es miembro de ALEC, propuso la SB1070. La redacción de esta ley se hizo en conjunto con CCA (Immigrants for sale) (Brave New Films, 2015). ${ }^{5}$ Entre el 2003 y 2015 se han producido 165 muertes en centros de detención federales, de las cuales 15 fallecieron en Eloy, sus muertes se atribuyen a suicido o asfixia (AZ Central, 2016).
} 
A inicios de 2009 el Departamento de Justicia inició una investigación federal con el fin de analizar las prácticas de control y detención del Sheriff Joe Arpaio. La investigación determinó que se habían producido abusos de poder al basar la detención de individuos de acuerdo con el perfil racial (Meissner et al., 2013; Castañeda, 2015). Después de la cancelación del Acuerdo 287g, en el 2012 se inició una demanda directa al sheriff del condado. La demanda se basaba en tres puntos principales: acciones policiales discriminatorias, en las que los latinos eran detenidos por motivos de raza, color u origen nacional; criminalización de grupos defensores de migrantes; prácticas discriminatorias en cárceles, como Tent City, contra reclusos de origen latino y con habilidades limitadas de inglés; (Meissner et al., 2013, p. 105).

A pesar de lo expuesto, la promulgación de la SB1070 continuó con las medidas de detención basadas en el perfil racial. El protocolo apuntaba a las siguientes características: personas de "color", personas que conduzcan camionetas-trokas, autos que tengan pegatinas en español, si había muchas personas en el auto y si las personas hablaban en español (V. Hernández, directora de CNL comunicación personal 13 de marzo de 2018). Las detenciones se realizaban generalmente en barrios con mayor población latina, como Maryvale. De hecho, como señalan Meissner et al. (2013), en este periodo un conductor latino en el Condado de Maricopa tenía entre cuatro y nueve veces más probabilidades de ser detenido por la policía que los conductores no latinos.

En noviembre de 2016 el demócrata Paul Penzone ganó las elecciones para ser Sheriff, venciendo a Arpaio, que ocupó el poder durante 24 años. Una de sus principales promesas de campaña fue retirar a el ICE de la cárcel de la 4ta avenida de Phoenix. La existencia del ICE en la cárcel local respondía al funcionamiento del Criminal Alien Program (CAP), el cual permite que agentes migratorios estén en cárceles locales.

El 17 de febrero de 2017, Penzone dio por terminado cualquier convenio con el ICE que facilitara su entrada a la cárcel local de Phoenix. Sin embargo, una semana después reactivó los acuerdos debido a la presión mediática y política que señalaba un aumento de inseguridad en Phoenix a causa de la población migrante indocumentada. La presencia del ICE en la cárcel local de Phoenix es problemática, ya que acelera los procesos de deportación. En este sentido, el panorama en Phoenix, Arizona, a inicios del 2018 era desalentador para la población migrante, debido a que las medidas antinmigración eran muy parecidas a las existentes durante el régimen de Arpaio.

\section{FORMAS SUTILES DE DESCAPITALIZACIÓN: MULTAS DE TRÁNSITO}

La descapitalización de los sujetos migrantes se produce a cualquier escala; la más fuerte y evidente es al entrar en un proceso de deportación, y la más invisible, que pasa desapercibida son las multas de tránsito. Sostenemos que los sujetos migrantes, independientemente de su condición legal, están expuestos a una descapitalización directa e indirecta, en la que las 
mujeres migrantes resultan ser las más afectadas. Esta reflexión surge alrededor de varios testimonios de mujeres que han sido detenidas y multadas recurrentemente por las fuerzas policiales. Estas prácticas de persecución y hostigamiento hacia la población migrante tienen como objetivo, más allá de promover miedo, obtener ganancias económicas que permitan sostener el modelo de control social continuo a través del endeudamiento en el que se ha convertido también el régimen de detención y deportación de migrantes.

El barrio de Maryvale concentra a la mayor población latina de Phoenix por lo que el incremento de la vigilancia y control está direccionado a este tipo de barrios, diversas investigaciones muestran que en barrios pobres y de clase media trabajadora es común encontrar estas prácticas en comparación con suburbios de población blanca (Golash-Boza, 2019; Gilman y Romero, 2018; Zarrugh, 2019). Durante los dos primeros años de la SB1070, la competencia de la policía de tránsito y la de los sheriffs, estaba difuminada. Generalmente las mujeres, o sus familiares, eran detenidas por policías de tránsito o sheriffs al conducir o ir de acompañantes. Entre las principales causas de arresto están las infracciones menores de tránsito, por ejemplo: exceso de velocidad, conducir sin licencia y desperfectos del vehículo.

Las detenciones por perfil racial relacionadas con cuestiones de tránsito vial, se transformaron en algo común. Como nos indicaba Sonia, migrante indocumentada de 40 años residente de Maryvale, un día, cuando regresaba a casa, un policía la detuvo sin motivo aparente, siendo víctima de perfil racial. El policía le solicitó su licencia de conducir y le preguntó si había bebido y fumado marihuana, ya que sus ojos estaban rojos. Sonia señaló que únicamente estaba cansada, sin embargo, la policía procedió con el arresto y la envió a la cárcel de la 4ta avenida, para posteriormente entregarla al ICE. Sonia no tenía antecedentes penales ni faltas migratorias, por lo que le concedieron una fianza de 1500 dólares americanos para salir en libertad y posteriormente presentarse ante un juez de migración. Sin embargo, no acudió a la corte de migración lo que significó tener una orden de deportación automática. Además de la fianza que pagó para permanecer en el país temporalmente tuvo que cancelar la multa de tránsito por no portar licencia de conducir.

La historia de Sonia representa una continuidad en las prácticas con las que opera la policía de Maryvale. La mayoría de las mujeres entrevistadas señalaron que era una cuestión de "suerte", según el tipo de policía que las detiene. Esas detenciones solían tener un sesgo de género, mucho más automático para los hombres que para las mujeres. Las preguntas de los oficiales de la policía, cuando detenían a las mujeres y encontraban que no tenían licencia, solían referirse a la composición familiar de su casa: número de hijos o hijas, edad de estos, si son ciudadanos o no. Es decir, la no detención apela comúnmente a la maternidad. No obstante, si bien las mujeres por lo general no eran detenidas, se veían obligadas constantemente a pagar multas por infracciones de tránsito. Esto se debía a que las placas del auto quedaban registradas en el sistema policial y, al tener el reporte de que pertenecían a personas indocumentadas, las multas al mismo auto solían ser recurrentes. 
Después de ocho años de vigencia de la ley SB1070 y del cambio de autoridades locales, la mayoría de los testimonios indican la existencia de un continuum en la detención y en las prácticas racistas hacia la población migrante, vemos cómo la raza y el género son utilizados como dispositivos de control de las poblaciones. Si bien las detenciones en la zona no son tan visibles como en la época de Arpaio - pues el amedrentamiento se producía en todo el espacio público (parques, centros comerciales, lugares de ocio)-, las detenciones continúan y se han intensificado las formas de control a través de las infracciones menores de tránsito.

Uno de los lugares en donde las prácticas racistas de la policía local son más visibles es en las afueras de las escuelas de Maryvale. Camila, migrante indocumentada de 38 años, fue detenida en 2015 por un policía al momento de dejar a sus hijos en la escuela. Si bien todos los autos se estacionaban en un lugar no autorizado para dejar a niños y niñas en la escuela, pero ella fue la única detenida.

Como un año duró ese policía quitando carros afuera de la escuela, era horrible, desde que me quitó el auto me tocó ir en bus para dejar a mis hijos, él me tenía fichada. Además, a las personas blancas que hacían eso nunca las paraba. Un día creo que le tocó una persona de "color" que sí tenía documentos y ahí se armó la grande [...] nunca nos quejamos en la escuela sobre el policía, yo tenía miedo [...] No podía manejar el auto porque esa vez me tocó pagar 650 dólares para sacarlo del corralón, no podía estar pagando esa cantidad siempre, decidí no arriesgarme (Camila, comunicación personal, 12 de febrero de 2018).

En la actualidad, el acoso policial continúa siendo una práctica común en el barrio de Maryvale. Fidela, migrante indocumentada de 46 años, señalaba que en diciembre de 2017 fue multada dos veces por el mismo policía en Maryvale en un corto intervalo de tiempo. La primera detención fue por no encender las luces de su auto mientras conducía, y una semana después, por no prender la luz de su placa. Poseer una licencia de conducir emitida en la década de los noventa y hablar inglés fluido evitó la detención en los dos casos, pero no así las multas por infracciones de tránsito.

Los testimonios reflejan con claridad los efectos y el peso social que genera el régimen de detención y deportación en las mujeres migrantes. Las diferentes dimensiones de poder que están inmersas dentro de estas detenciones sutiles, denotan una serie de prácticas violentas, discriminatorias, y además se evidencia de qué forma la maternidad es utilizada como un filtro para ser o no detenida. En este sentido, el accionar policial está atravesado por prácticas patriarcales ya que la libertad de las mujeres migrantes indocumentadas depende de la obligatoriedad de la maternidad.

En este sentido, tanto si se está inmersa plenamente en el "caos" de la deportación, como si solo se es candidata a la misma, la deportabilidad termina configurando cuerpos dóciles y disciplinados (Boehm, 2016) que tratan de habitar en las normas sin ser detectados, pues el 
miedo no solo es a la expulsión sino al castigo económico constante en un contexto de hostigamiento, miedo y persecución.

\section{LAS FORMAS DE DESCAPITALIZACIÓN EN LOS PROCESOS DE DEPORTACIÓN}

La economía de la "ilegalidad" se sostiene a través de la aplicación de diversas tecnologías de poder, como por ejemplo la detención y la deportación. En esta sección nos centraremos en explicar las diferentes formas de descapitalización y desposesión que se generan al momento en que las mujeres migrantes mexicanas indocumentadas están inmersas en un proceso de deportación, y qué implicaciones tiene tanto a nivel individual como familiar. Partimos de una de las expresiones más repetidas al momento de conversar con las entrevistadas, con respecto a cuál sería su accionar al entrar en un proceso de deportación; ellas señalaron firmemente estar dispuestas a "pelear el caso", lo cual está en relación directa con poseer un fuerte capital económico y preparación en conocimiento de derechos para poder afrontar el confuso proceso legal que es la deportación. Con base en lo anterior, explicaremos qué significa "pelear el caso desde afuera", que se refiere a formar parte de Alternatives to Detention Program (en adelante ATD), y qué significa "pelear el caso desde adentro", que hace alusión a estar detenida en un centro de detención migratorio. De esta manera, queremos explicar de qué forma funciona la industria de la detención a través de la criminalización de los sujetos migrantes que tiene fuertes connotaciones de género.

\section{Peleando el caso "desde afuera"}

El régimen de deportación y el modelo de control se reinventa constantemente con el fin de perfeccionar prácticas de vigilancia y mecanismos de control que posibiliten una acumulación de capital. A pesar de la dureza de los procedimientos, hay ciertas excepcionalidades que permiten pelear mejor los casos, sobre todo estando afuera de los centros de detención migratorios.

Sin embargo, para poder pelear el caso desde afuera, la mayoría de las mujeres exponen que deben resistir los interrogatorios que realizan los agentes migratorios en el momento que están detenidas. El objetivo del ICE es encontrar suficientes pruebas en el interrogatorio para poder acelerar la deportación. Los y las migrantes tienen derecho a guardar silencio y a solicitar la representación de un abogado. Algunas de las mujeres entrevistadas conocen este derecho, pero al momento de su detención los nervios, el estrés y el discurso que maneja el ICE, las confunde. El siguiente testimonio de Gloria, migrante indocumentada de 46 años, ejemplifica la violencia explícita a la que están expuestas:

Me tocó un agente de migración muy grosero; por 40 minutos me gritó e insultó. Él me hacía muchas preguntas, sobre cómo había entrado, de dónde venía, y yo le decía: "no te voy a contestar, tengo derecho a permanecer en silencio, quiero ver a mi 
abogado”. Él me respondía: “¡Tú no tienes derechos, ustedes no tienen derechos!”. Me preguntaba cuántos hijos tenía; luego me dijo que estaba mal psicológicamente, que estaba loca si creía que tenía derechos. Luego buscó en el internet, desde su teléfono, y me mostró una frase que decía: "El respeto al derecho ajeno es la paz", me lo leyó como 20 veces y me decía: “¿quién lo dijo?” yo le decía: “¡no te voy a contestar nada!”, luego me dijo: "lo dijo Benito Juárez, mexicanita" [...] Ahí te humillan, te insultan. Luego me comenzó a decir "ok, ¿no quieres contestar? te vamos a dejar en la cárcel unos cinco años, por lo que acabas de hacer, ¿sabes que estás violando la ley?”. Le dije: "ni modo no te voy a contestar". Él se enojaba más. [...] Pues no sé, te entran los nervios, te da risa, ganas de llorar. En un momento te trabajan psicológicamente que te hacen pensar que tú no tienes derechos, y que es verdad lo que ellos te dicen y que tal vez sí tenías que contestar todas esas preguntas, entras en una confusión bien fea, es desesperante (Gloria, comunicación personal, 14 de febrero 2018).

La forma de operar del ICE viola directamente los derechos humanos, ya que al percibir a los y las migrantes como desechables y sin derechos, están deshumanizando sus vidas. Además, denota la puesta en práctica de un racismo institucional y de procesos de racialización y de discriminación hacia los sujetos migrantes que se sustentan bajo relaciones desiguales de poder. Lo que refleja este testimonio es la forma en que las mujeres mexicanas, migrantes e indocumentadas, están expuestas a diversos tipos de discriminación y de desigualdad: por su género, raza, clase, nacionalidad y estatus migratorio. Frente a este escenario de despojo, de inseguridad y de violencia de género, estas mujeres exponen que "pelear el caso" también significa estar conscientes de que tienen derechos y, además, denotan que su única arma es la resistencia.

Ahora bien, el ICE ha implementado una serie de excepciones para dejar en libertad a personas que no representan una amenaza a la comunidad, y que además puedan garantizar su presencia en futuras audiencias, y que están basadas en el dispositivo de género. En este sentido, pueden salir bajo fianza, usar grillete electrónico, y además, en algunos casos, deberán realizar check in regularmente en el ICE. Estos programas son conocidos como ATD. La mayoría de las mujeres entrevistadas que han sido arrestadas por el ICE, han salido en libertad bajo estas condiciones. Con los programas ATD existe, igualmente, una fuerte connotación de género en el momento en que los agentes migratorios y los jueces deciden con base en el género, qué migrantes califican, pues lo hombres en su mayoría son llevados a centros de detención a pesar de no tener antecedentes criminales.

Gómez et al. (2017) señalan que el ATD está dirigido principalmente a mujeres que son madres, reforzando de esta forma los roles de las migrantes latinas como madres, aunque al mismo tiempo se les niega el derecho de cumplir con esos roles. Paradójicamente, este tipo de programas se presentan a sí mismos con un carácter de supuesto trato más "humano", pero en realidad "refuerza los estereotipos de que las mujeres latinas son madres, ocultando así sus otras posiciones sociales como trabajadores migrantes y como personas con derechos" (Salcido y Menjívar 2012 citadas en Gómez et al., 2017, p. 6). 
Existen diversas formas en la que una persona es puesta en libertad mientras se inicia su proceso de deportación. La más común es salir bajo fianza para no ir a un centro de detención. En este caso, el o la juez/a de migración fija un monto de acuerdo con ciertos parámetros centrados en la figura del "buen migrante", de ahí que si la persona representa un alto riesgo de fuga la fianza aumenta. Según varios testimonios existen fianzas que van de los 1000 hasta 50000 dólares, además es requisito que la persona que cancele la misma tenga un número de seguro social.

Derivado de lo anterior, es casi imposible que las personas detenidas tengan esa cantidad de dinero automáticamente. Ante esto, la mercantilización de la detención y de la "ilegalidad" han provocado que varias empresas financieras otorguen préstamos para pagar las fianzas, con el requisito de usar un grillete electrónico para garantizar la devolución del dinero. De esta forma, hay una externalización del control de estas empresas que controlan y vigilan a los individuos. Así, en el caso de que se alejen de la zona dictaminada por el ICE, las empresas financieras cumplen el papel de policía comunicando inmediatamente al ICE la violación de lo acordado. La carga simbólica de llevar un grillete electrónico estigmatiza la vida de las mujeres, ya que muchas veces son percibidas como criminales, por parte de sus familiares o de la comunidad en general.

En la misma línea, el ICE también coloca grilletes electrónicos, las mujeres que están dentro de este programa son aquellas que el juez no puso fianza pero que necesitan ser monitoreadas constantemente. A su vez, existen personas que además de salir bajo fianza deben realizar check in, otras personas únicamente deberán presentarse frente a las cortes migratorias cuando dictaminen los jueces de migración.

Vemos, por lo tanto, cómo el cuerpo de estas mujeres indocumentadas es controlado por empresas privadas que trasladan indirectamente la prisión a la vida cotidiana, ya que administran el tiempo y espacio de las migrantes. Las grandes corporaciones continúan mercantilizando los cuerpos vulnerables, entre ellos el de las mujeres y han encontrado un nicho de poder y ganancia en la detención y monitoreo de la población migrante. Sin duda, este sistema viciado está cargado de una violencia legal, simbólica, física y estructural (Menjívar y Abrego, 2012).

Ahora bien, "pelear el caso" no implica que estas mujeres se quedarán en Estados Unidos, significa estar inmersa en un aparataje legal y burocrático en el que deben demostrar por qué quieren quedarse. Según los expertos legales, esta frase se transforma en una forma de "ganar tiempo", ya que casi ninguna persona puede arreglar su situación migratoria debido a los estrictos y casi imposibles requisitos para alcanzar la residencia, y posteriormente, la ciudadanía.

Las personas que pelean su caso "desde afuera" de los centros de detención se quedan en Estados Unidos, un tiempo de alrededor de uno a dos años, como máximo. Aquellas personas que no califican para fianza, o que no tienen el dinero para pagarla, son descartadas de la 
maquinaria de hacer dinero, y son llevadas directamente a un centro de detención. Según los expertos legales consultados durante la investigación, más de la mitad de las personas que están detenidas podrían estar libres si pudieran contratar un abogado. ${ }^{6}$

\section{Peleando el caso "desde adentro": deshumanización carcelaria}

La institucionalización de la detención produce una descapitalización y precarización de las mujeres migrantes mexicanas indocumentadas, de sus familias o seres queridos. De esta forma, la detención indefinida es una de las armas más fuertes que posee el régimen de control y deportación. En este caso, aquellos sujetos migrantes que no califican para obtener una fianza, o bien que no tienen cómo pagarla, deben estar dispuestos a quedarse en un centro de detención sin tiempo límite. Este hecho junto con el trato vejatorio y deshumanizante de la cárcel explica la dificultad de "pelear el caso" desde adentro.

Las leyes migratorias y el régimen de deportación han creado un modelo carcelario en el que grandes corporaciones se benefician de la detención de la población migrante indocumentada, residentes o solicitantes de asilo. Los centros de detención se caracterizan por ser formas extendidas del poder estatal, control social y castigo en la era neoliberal (Bosworth, 2014; Fassin, 2005 citados en Gómez et al., 2017). Suelen estar localizados en lugares remotos dificultando la comunicación de las personas detenidas con sus familiares.

Los centros de detención operan con las mismas prácticas de control y vigilancia que tienen las cárceles para controlar a los reclusos. Usan tácticas disciplinarias y de control hacia los individuos mediante el monitoreo de cámaras, horarios estrictos de visitas, implementación de castigos, prácticas de aislamiento, inspecciones después de comer o antes de dormir. Es decir, la población migrante es completamente criminalizada.

Además de todo el disciplinamiento en el que están inmersos los detenidos, hay que recalcar que la infraestructura y sus constantes cambios también recrean un ambiente de institución total. Actualmente, los centros de detención migratoria se están convirtiendo en cárceles federales al adoptar también su infraestructura carcelaria. Varias de las entrevistadas señalan que desde febrero 2018 habían notado remodelaciones en la sala de visitas y nuevas reglas. Es el caso de Margarita, migrante indocumentada de 49 años que junto con sus tres hijas de ocho, seis y cinco años visita cada semana a su esposo detenido en el Centro de Detención Eloy desde hace un año. Margarita recuerda que antes de febrero de 2018 la visita era diferente, ya que el contacto con su pareja era directo. Ahora la infraestructura y las reglas son otras debido a que colocaron una separación con vidrio, de forma que los detenidos no pueden tener contacto físico con las visitas y, además, la comunicación se da por medio del uso de teléfonos fijos colocados de uno y de otro lado.

\footnotetext{
${ }^{6} \mathrm{El}$ costo de servicios legales sobre casos de migración oscila entre los 6000 y 7000 dólares.
} 
Otra forma de disciplinar los cuerpos es por medio del aislamiento. La mayoría de los detenidos no reciben visitas, ya que sus familiares tienen miedo de también ser detenidos debido a su estatus legal indocumentado. Cuando los hombres son detenidos, son visitados por sus parejas con más regularidad. La situación empeora cuando las mujeres están detenidas ya que no reciben visitas por parte de sus parejas. A diferencia de las cárceles federales, las personas pueden visitar a los detenidos en los centros de detención migratoria presentando su pasaporte. Sin embargo, CCA ha notificado a diversas personas, por medio de cartas, el cambio de reglas en las visitas señalando que deben presentar una identificación del estado, lo que ha incrementado el miedo de los familiares a exponerse a una posible detención.

El aislamiento no solo es físico, sino también tecnológico, ya que aquellas personas que están en centros de detención también se someten a formas “indirectas" de descapitalización, tal es el caso del alto costo de las llamadas telefónicas al interior de los centros. En varios testimonios se señala el pago de altas sumas de dinero (200 dólares americanos) por haber recibido llamadas de familiares desde el centro de detención.

Varias personas entrevistadas han señalado que el trato de CCA en el Centro de Detención Eloy es inhumano y alarmante, ya que los detenidos están en constante aislamiento y desprotegidos debido a que en las instalaciones no hay ninguna instancia en la que una persona pueda poner una queja por mal trato o abuso. Al ser un centro privatizado, la responsabilidad del trato de cada detenido está a cargo de una empresa privada, y no del ICE. Tal es el caso de Dulce, migrante indocumentada de 33 años, quien está casada con un migrante indocumentado, tiene cuatro hijos ciudadanos de 15, 14, 10 y 5 años. En enero de 2010, tomaron la decisión de autoexpulsarse de Phoenix, Arizona y regresar a su lugar de origen Guanajuato,México. Sin embargo, a inicios del 2012 dicidieron retornar a Phoenix, debido a la falta de acceso a servicios básicos, educación, y el desempleo que atravesaron. Dulce, al retornar por un cruce irregular fue detenida por la patrulla fronteriza y, posteriormente, fue encarcelada en el Centro de Detención Eloy. A continuación nos narra su experiencia en Eloy.

Me entregaron ropa interior usada, sábanas usadas; no había calefacción, era helado, horrible. Cuando estás ahí te levantas 4:30 a.m. Te levantan para desayunar y tú no tienes hambre, no te da hambre, pues yo no tenía hambre por estar pensado ¿qué estoy haciendo aquí? ¿cómo están mis hijos? ¿estarán comiendo o no? Lloro. Entonces ¿cómo vamos a poder comer a gusto? Simplemente no se puede. Suspiro, es difícil es suspiro, es algo que dices "Diosito yo nunca hice nada malo e igual tengo que estar aquí encerrada, separada de mis hijos". En ese lugar pierdes toda tu dignidad, ¡ay!, es muy feo. Pensar en las cosas es algo doloroso, lo más duro es quizás aguantar todas esas cosas de cómo te hablan, te dicen "rápido" y te revisan, a mi casi a diario me revisaban después de que salíamos de la comida. No es nada más de cómo te revisan si no también cómo tocan tu cuerpo, y yo decía “iqué me voy a estar robando!”. Yo sé que había personas que sí se llevaban la comida, las mirábamos llevarse a escondidas, 
pero era comida, ellos no nos daban de comer tres veces al día. Vivía con miedo, aparte que no sabía nada de mi caso, cada semana llegaba "el deportador", así lo llamaban las señoras que estaban más tiempo ahí, él te preguntaba si querías seguir esperando la audiencia con un juez o si firmabas y ya te ibas pa' fuera (Dulce, comunicación personal, 14 de marzo 2018).

Al hablar de detención de mujeres, encontramos que el disciplinamiento de sus cuerpos en esta institución también se debe a prácticas de abuso físico, mental y sexual. Estas formas de abuso se dan bajo la justificación de que son "chequeos" o "protocolos" carcelarios. Las mujeres detenidas tienen poco control de sus vidas al interior. Sin duda, el encarcelamiento es una experiencia traumática en la que sus cuerpos son juzgados, invadidos y mercantilizados. Además, las condiciones inhumanas e insalubres de los centros de detención producen un ambiente de estrés, desesperación y desorientación. Frente a estos escenarios de vulnerabilidad la seguridad y la justicia no están garantizadas para las mujeres migrantes.

Por medio de estas prácticas coercitivas y la visita constante de "el deportador" se prueba cuánto tiempo una persona puede resistir detenida en condiciones inhumanas y precarias, forzándolas a firmar su deportación. En este sentido, y retomando a Wacquant (2010), se evidencia una penalización de la pobreza y de la "ilegalidad", que se asienta en un proyecto neoliberal apoyada en grandes corporaciones quienes ven al ser humano como mercancías. La deportabilidad, la detenibilidad y la "ilegalidad" son formas de violencia que se acentúa en los centros de detención, ya que son espacios que vulneran aún más la vida de los y las migrantes.

\section{DE LA DESCAPITALIZACIÓN A UNA CRISIS MULTIDIMENSIONAL}

En este apartado nos interesa explicar de qué manera afecta mayoritariamente a las mujeres estar inmersas ellas o sus familiares en un proceso de deportación. Sostenemos que la deportabilidad y los procesos de descapitalización provocan una precarización de la vida. Por un lado, se produce una descapitalización económica, y por otro, una desposesión emocional. Sin embargo, surgen diversas estrategias para sobrellevar este proceso de despojo.

Sobrevivir a un proceso de deportación implica una descapitalización que afecta directamente las relaciones familiares. Lo que hemos observado es que cuando una persona está inmersa en un proceso de deportación o es detenida, se produce una reestructuración en los roles de género dentro de la familia. Por ejemplo, ya sea en familias monoparentales o biparentales, por lo general los hijos o hijas que están en edad de trabajar, sin importar su estatus legal, deben insertarse en el mercado laboral para pagar las grandes deudas que implica hacer frente a la deportación.

En el caso de las parejas de estas mujeres que están en proceso de deportación sin estar encarcelados, y que deben presentarse regularmente a corte y check in, hemos detectado que 
esto ocasiona una crisis multidimensional que afecta, principalmente en las mujeres. Primero, debido al riesgo que significa trabajar con un número de seguro social fraudulento, sus parejas deciden buscar trabajo en el sector informal, mientras que otros simplemente no buscan empleo. Esto ocasiona que los ingresos familiares disminuyan y frente a este escenario las mujeres deben trabajar dobles jornadas, además del trabajo doméstico y de cuidados que está a su cargo.

Segundo, a nivel de hogar se generan diversas estrategias para la provisión de bienestar y la reproducción social de la vida, el motivo fundamental que mueve a las mujeres para el sostenimiento de la vida parte de esa necesidad de crear un sistema de aprovisionamiento de recursos para poder sobrevivir. Por tal motivo, han adoptado formas de supervivencia similares a las que tenían en México, por ejemplo: compran alimentos al por mayor y preparan comida en casa, como tortillas, para alivianar los gastos.

Tercero, algunas mujeres adoptan como "estrategia" la compra de un seguro social fraudulento, que en el mercado negro oscila entre los 400 a 600 dólares, a fin de conseguir un mejor empleo que aumente los ingresos familiares. Cuarto, debido a que sus parejas no se pueden arriesgar a una posible detención por conducir, son las mujeres, en la mayoría de los casos levantados, quienes los transportan.

Quinto, la deportabilidad y la detenibilidad configuran una cultura de miedo, la cual tiene un sesgo de género, debido a que las mujeres tienen temor a convertirse en madres solteras (Dreby, 2015) debido a la poca autonomía económica que tienen. Sexto, las mujeres también se ven obligadas a reforzar la masculinidad de su pareja (Hochschild, 1990), debido a que el proceso de deportación produce procesos de desgaste de la masculinidad hegemónica y patriarcal de su pareja. En resumen, todos los factores mencionados ocasionan una crisis en el uso del tiempo de las mujeres, disminuyendo su calidad de vida y precarizando aún más sus vidas.

En los casos en los que la pareja ya había sido deportada en el momento de la entrevista, nos percatamos de que que existía un proceso de empobrecimiento constante. Es decir, los procesos de descapitalización también se perciben después de la deportación, nos referimos a la pérdida de bienes muebles e inmuebles que estuvieron a nombre de la pareja y que no se puede realizar el traspaso legal. A pesar de verse inmersas en crisis multidimensionales, estas mujeres decidieron permanecer en Estados Unidos y no retornar a México. Su principal argumento fue tener mayor independencia, seguridad y oportunidades que en su lugar de origen.

En el caso de las mujeres que están en proceso de deportación, se evidenció cómo el uso del grillete electrónico les impedía insertarse en el mercado laboral debido a la carga simbólica y estigma que evoca el dispositivo de control. A su vez, existía una desposesión emocional y psicológica debido a que su futuro se tornaba incierto, además del temor que sentían al imaginarse separadas de sus hijos o hijas. 
En el escenario en el que la persona deportada es mujer, la crisis de la reproducción social que genera la deportación es aún mayor. En diferentes testimonios pudimos detectar que son las hijas de estas mujeres, sin importar su edad, las que usualmente asumían el trabajo doméstico y de cuidados en sus hogares. En aquellas madres solteras que tenían familia en Phoenix el trabajo de cuidados estaba a su cargo.

Derivado de lo anterior, la custodia y el cuidado de los hijos es un tema sensible, traumático y controversial. Existe temor por parte de las mujeres al imaginarse una separación abrupta (Golash-Boza, 2019; Dreby, 2015). Sin embargo, este miedo las ha impulsado a realizar trámites legales para delegar la custodia de sus hijos. Diversas activistas de organizaciones pro migrantes señalan que tienen en custodia legal a varios hijos e hijas de mujeres migrantes indocumentadas que no tienen familia en Estados Unidos. Además, surgen estrategias colectivas y cadenas de cuidado, las mujeres que asisten a estas organizaciones, y que son indocumentadas, se han ofrecido a ser cuidadoras a pesar de no tener la custodia legal. Cabe recalcar que, a pesar de estar inmersas en procesos de despojo, estas mujeres se dan el tiempo para formar parte de organizaciones pro migrantes. $\mathrm{La}$ reproducción social de la vida no solo debe ser vista por el lado económico sino también desde lo social y lo político y, precisamente, estas mujeres están tejiendo diversos lazos comunitarios para poder sobrellevar el miedo y la amenaza constante de la deportación (Narotzky, 2004; Mahmood, 2008).

La descapitalización y la crisis multidimensional que atraviesan las mujeres migrantes, sus familiares y seres queridos, se perciben en los efectos después de la deportación y la decisión de retorno. La consolidada industria del cruce ilegal de las fronteras también forma parte de la economía de la "ilegalidad" e implica una serie de eventos violentos y deshumanizantes que los sujetos migrantes deben atravesar (Lee, 2018; Gerard y Pickering, 2014). El cambio en la frontera es evidente, y el reingreso es peligroso, no solo por poder ser objeto de nuevas detenciones y violencias sino por la presencia del narco en la frontera, además de las altas sumas de dinero que requiere la contratación de un coyote. Por tal motivo, varios familiares deportados de estas mujeres han tomado la decisión de vivir en una ciudad fronteriza, usualmente Puerto Peñasco que está a cinco horas manejando de Phoenix, Arizona, con el fin de iniciar un negocio, recibir visitas de familiares que puedan viajar a México. Aquellas mujeres solteras y que no tienen familia en Phoenix, usualmente retornan a su lugar de origen.

En este sentido, vemos cómo los procesos de acumulación de capital afectan los procesos de reproducción de la vida. La economía de la "ilegalidad" configura un círculo vicioso, ya que somete a los y las migrantes a pagar grandes deudas, lo que lleva a sus allegados a trabajar de una manera más flexible y precaria. La vida de estas mujeres se transforma en un constante caos ya sea cuando ellas o sus parejas están inmersas en un proceso de deportación. El género se entrecruza con otras formas de dominación y opresión, como la deportabilidad, detenibilidad, "ilegalidad", para facilitar la explotación económica y la 
configuración de sujetos explotables y vulnerables. Como lo señala Boehm (2016), por medio de la deportación el Estado no solo disciplina a los sujetos migrantes deportados -que generalmente son hombres-, sino también a sus familiares, además de someterlos a procesos de empobrecimiento debido a una constante descapitalización.

\section{CONCLUSIONES}

La economía de la "ilegalidad" se sostiene por medio de la descapitalización de los sujetos migrantes diferenciada por género. Es decir, la "ilegalidad" no solo ofrece mano de obra barata, sino también contribuye a la creación de un sistema de enriquecimiento estatal, corporativo y global en el que, por medio de multas, fianzas, detenciones, se beneficia directamente de los sujetos migrantes. El sistema capitalista ha encontrado una nueva forma de acumulación de capital global al someter obligatoriamente a los sujetos migrantes, y específicamente a mujeres migrantes indocumentadas, a procesos de descapitalización sutiles y violentos. De igual manera, está acumulación de capital produce daños irreparables en la vida de la población migrante, al desposeerlos de seguridad física y psicológica. En este sentido, estos cuerpos dóciles, racializados, generizados y etiquetados como "ilegales" se han transformado en el centro de acumulación de este régimen de deportación.

Sostenemos además que estos procesos de descapitalización no empiezan con el proceso de deportación, sino con las multas de tránsito recurrentes a las que está expuesta la población migrante y, que las mujeres son las más afectadas. Desde ahí debemos reflexionar a dónde va el dinero de las multas, quién se está enriqueciendo; ya que es posible que los sujetos migrantes, y específicamente las migrantes mexicanas indocumentadas, estén sosteniendo indirectamente la vigilancia policial que es evidente en barrios como el de Maryvale. Además, si partimos de una perspectiva más amplia, comprenderemos que la descapitalización y la deshumanización de los sujetos migrantes empieza mucho antes, desde el inicio del proyecto migratorio, pues se necesita de fuertes sumas de dinero y la contratación de coyotes para llevar a cabo el traslado, y además, repensar un posible retorno después de la deportación. Esto se conecta con la idea de una descapitalización y endeudamiento continuo, transnacional, que se asienta en una economía sumergida, pero al mismo tiempo legitimada por el régimen de la deportación.

Por otro lado, al ingresar en un proceso de deportación y querer "pelear el caso", las estrategias que se despliegan están en relación directa con el capital económico de cada sujeto migrante diferenciada por género, de la estructura y negociaciones familiares para poder hacer frente a todos los requisitos impuestos por las leyes migratorias.

Las fianzas son altas cantidades de dinero que los y las migrantes deben pagar si quieren salir en libertad. La acumulación de capital global, junto al régimen de deportación, ha creado alianzas con instituciones financieras para dar préstamos a migrantes, y a su vez 
controlar sus movimientos con grilletes electrónicos. Lo que evidenciamos es que los sujetos migrantes están hipotecando su libertad.

La penalización de la migración debido a la producción legal de la "ilegalidad" ha provocado que los sujetos migrantes sean vistos como mercancías. No importa si han cometido un delito, lo que interesa es sustraer la mayor cantidad de ganancia en la detención. No es de extrañar la proliferación de políticas que instan a la detención indefinida de migrantes, convirtiendo a los centros de detención en "campos de concentración" cuyas prácticas internas deshumanizan aún más la vida de los y las migrantes.

La descapitalización y la desposesión afectan mayoritariamente a las mujeres migrantes indocumentadas ocasionando una crisis multidimensional en sus vidas. La deportabilidad y detenibilidad precariza la vida de estas mujeres y las somete a procesos de empobrecimiento, de despojo emocional constante y crisis del uso del tiempo. Programas como el ATD, asientan las desigualdades sociales de las mujeres migrantes, provocando un control de sus cuerpos en el hogar, espacio laboral, espacio público. Hay que ser críticos respecto a este tipo de programas que se presentan como "humanistas" pero en el fondo son formas de reinvención del capitalismo y del mercado global de la detención para lucrar del cuerpo de las mujeres haciendo, generalmente, alusión a la maternidad. A la vez, son estas mujeres las que han creado diversas estrategias para poder sobrevivir a la amenaza de la deportación, y que a pesar de su vulnerabilidad son resistentes, desafiando al poder por medio de su capacidad de acción y agencia.

En definitiva, consideramos que la economía de la "ilegalidad" no solo se sostiene de la mano de obra barata y flexible de los sujetos migrantes, sino también de la descapitalización que se va produciendo del mismo, lo que provoca un círculo vicioso de explotación diferenciada por género. Este régimen global de control y deportación apoyados en la producción legal de la "ilegalidad", ha encontrado un nicho de poder y acumulación de capital al criminalizar los cuerpos de las mujeres migrantes indocumentadas. Por tal motivo, es clave reflexionar de qué forma este régimen está acumulando capital a nombre de la institucionalización del control migratorio.

\section{REFERENCIAS}

Aquino, A. (2015). "Porque si llamas al miedo, el miedo te friega": La ilegalización de los trabajadores migrantes y sus efectos en las subjetividades. Estudios Fronterizos, nueva época, 16(32), 75-98. Recuperado de https://doi.org/10.21670/ref.2015.32.a03.

AZ Central. (29 de noviembre de 2016). Another death at Eloy migrant-detention center. Recuperado de https://eu.azcentral.com/story/news/politics/borderissues/2016/11/28/another-death-eloy-migrant-detention-center/94574478/

Boehm, D. (2016). Returned: Going and Coming in an Age of Deportation. Oakland: University of California Press. 
Brave New Films. (27 de agosto de 2015). Immigrants for sale [Video]. Recuperado de https://www.youtube.com/watch?v=gF12SgkQKKk.

Butler, J. y Athanasiou, A. (2013). Dispossession. The Performative in the Political. Cambridge: Polity Press.

Calavita, K. (2004). “Un ejército de reserva de delincuentes": la criminalización y el castigo económico de los inmigrantes en España. Revista Española de Investigación Criminológica, (2), 1-15. https://doi.org/10.46381/reic.v2i0.16

Castañeda, A. (2015). La Política Migratoria de Estados Unidos desde la perspectiva federal. Reporte del Observatorio de Legislación y Política Migratoria. En A. Castañeda (Elab.), Reporte del Observatorio de Legislación y Política Migratoria, (pp. 2-26) México: Colegio de la Frontera Norte. Recuperado de https://www.colef.mx/wpcontent/uploads/2015/10/FINAL-Reporte-Politica-migratoriaaa.pdf

Cornelius, W. (2012). Evaluación reciente de la política de control de la inmigración estadounidense: lo que los inmigrantes mexicanos pueden contarnos. En A. Izquierdo y W. Cornelius (Eds.), Políticas de control migratorio. Estudio comparado de España y EE. UU., (pp. 31-43). Barcelona: Bellaterra.

Coutin, S. (2000). Legalizing Moves: Salvadoran Immigrants' Struggle for U.S. Residency. Ann Harbor: University of Michigan Press.

Coutin, S. (2003). Borderlands, Illegality and the Spaces of Non-existence. En R. Perry y B. Maurer (Eds.), Globalization and Governmentalities, (pp. 171-202). Estados Unidos de América: University of Minnesota Press.

De Genova, N. (2002). Migrant "illegality" and deportability in everyday life. Annual $\begin{array}{llll}\text { Review of Anthropology, } & \text { 31(1), }\end{array}$ https://doi.org/10.1146/annurev.anthro.31.040402.085432

De Genova, N. (2016). Detention, Deportation, and Waiting: Toward a Theory of Migrant Detainability (Global Detention Project Working Paper No. 18). Recuperado de https://www.globaldetentionproject.org/detention-deportation-waiting-toward-theorymigrant-detainability-gdp-working-paper-no-18

De Genova, N. y Peutz, N. (Eds.). (2010). The Deportation Regime: Sovereignty, Space, and the Freedom of Movement. Durham: Duke University Press.

Dreby, J. (2015). Everyday illegal: When Policies Undermine Immigrant Families. Oakland, CA: University of California Press.

Geertz, C. (1987). La interpretación de las culturas. Barcelona: Gedisa.

Gerard, A. y Pickering, S. (2014). Gender, Securitization, and Transit: Refugee Women and the Journey to the EU. Journal of Refugee Studies, 27(3), 338-359. https://doi.org/10.1093/jrs/fet019 
Gilman, D. y Romero, L. A. (2018). Immigration Detention, Inc. Journal on Migration and Human Security, 6(2), 145-160. https://doi.org/10.1177/2311502418765414

Golash-Boza, T. (2015). Deported. Immigration policing disposable labor and global capitalism. New York: New York University Press.

Golash-Boza, T. (2019). Punishment Beyond the Deportee: The Collateral Consequences of $\begin{array}{llll}\text { Deportation. American } \quad \text { Behavioral } & \text { Scientist, } & \text { 63(9), }\end{array}$ https://doi.org/10.1177/0002764219835259

Golash-Boza, T. y Hondagneu-Sotelo, P. (2013). Latino immigrant men and the deportation crisis: A gendered racial removal program. Latino Studies, 11(3), 271-292.

Gómez, A., Menjívar, C. y Staples, W. (2017). "Humane” Immigration Enforcement and Latina Immigrants in the Detention Complex. Feminist Cronology, 12(3), 269-292. https://doi.org/10.1177/1557085117699069

Harvey, D. (2003). The New Imperialism. England: Oxford University Press.

Hochschild, A. (1990). The Second Shift: Working Parents and the Revolution at Home. New York: Penguin Books.

Kanstroom, D. (2000). Deportation, Social Control, and Punishment: Some Thoughts about Why Hard Laws Make Bad Cases. Harvard Law Review, 113(8), 1890-1935. Recuperado de https://www.jstor.org/stable/1342313?seq=1\#metadata info tab contents

Lee, A. (2018). US-Mexico Border Militarization and Violence: Dispossession and Disorganization of Undocumented Laboring Classes from Puebla Mexico. Migraciones Internacionales, 9(4), 211-238. Recuperado de https://doi.org/10.17428/rmi.v9i35.444

Mahmood, S. (2008). Teoría feminista y agente social dócil: Algunas reflexiones sobre el renacimiento islámico en Egipto. En L. Suárez y A. Hernández (Eds.), Descolonizando el feminismo. Teoría y práctica desde los márgenes, (pp. 165-221). Madrid: Cátedra.

Martin, L. (2011). Technologies of apprehension: the family, law, security, and geopolitics in us noncitizen family detention policy and practice (Tesis doctoral para obtener el grado de Doctora en Geografía). Universidad de Kentucky. Recuperado de http://uknowledge.uky.edu/gradschool_diss/138

Meissner, D., Kerwin, D., Chishti, M. y Bergeron, C. (2013). Immigration Enforcement in the United States: The Rise of a Formidable Machinery. Washington, D. C.: Migration Policy Institute. Recuperado de https://www.migrationpolicy.org/research/immigrationenforcement-united-states-rise-formidable-machinery

Menjívar, C. (2014). Immigration Law Beyond Borders: Externalizing and Internalizing Border Controls in an Era of Securitization. Annual Review of Law and Social Science, 10, 353-369. https://doi.org/10.1146/annurev-lawsocsci-110413-030842 
Menjívar, C. y Abrego, L. (2012). Legal Violence: Immigration Law and the Lives of Central American Immigrants. American Journal of Sociology, 117(5), 1380-1421.

Montoya, E., Ochoa, A. y Woo, O. (2014). “A Headache Every Day since the New Law”: Mexican Women in the Hair Salon Business and Anti-immigrant Policies in Arizona. Migraciones Internacionales, 7(26), 134-164. Recuperado de https://doi.org/10.17428/rmi.v7i26.673

Narotzky, S. (2004). Reproducción social. En S. Narotzky (Autor), Antropología económica nuevas tendencias, (pp. 223-266). Barcelona: Editorial Melusina.

Pujal, M. y Amigot, P. (2010). El binarismo de género como dispositivo de poder social, corporal y subjetivo. Quaderns de Psicología. International journal of psychology, 12(2), 131-148. Recuperado de https://ddd.uab.cat/record/65040

Sassen, S. (2003). Contrageografias de la globalización, género y ciudadanía en los circuitos transfronterizos [Trad. A. Pastrana Izquierdo, C. Laudano, A. Pérez Orozco y L. Núñez]. Madrid: Traficantes de Sueños.

The Demographic Statistical Atlas of the United States. (10 de diciembre de 2017). Overview of Maryvale, Phoenix, Arizona (Neighborhood). Recuperado de https://statisticalatlas.com/neighborhood/Arizona/Phoenix/Maryvale/Overview

Torre, E. (2016). Explaining State and Local Anti-Immigrant Policies in the United States: The Case of Arizona's SB 1070. Migraciones Internacionales, 8(30), 38-63. Recuperado de https://doi.org/10.17428/rmi.v8i3.612

Wacquant, L. (2010). Las dos caras de un gueto [Trad. M. Mayer, B. Borgo, M. Silva, M.G. Ubaldini y J. Varela]. Buenos Aires: Siglo XX Editores.

Zarrugh, A. (2019). The Development of US Regimes of Disappearance: The War on Terror, Mass Incarceration, and Immigrant Deportation. Critical Sociology, 46(2), 257-271. Recuperado de https://doi.org/10.1177/0896920519826640 